\title{
WOMEN IN ACADEMIC ATMOSPHERIC SCIENCES
}

\author{
by David MacPhee and Silvia Sara Canetto
}

\begin{abstract}
A survey of U.S. atmospheric sciences doctoral programs finds that women are underrepresented among its faculty (17\%) as well as among individuals who, having completed the doctorate, pursue academic careers (20\%).
\end{abstract}

$\mathrm{T}$ here are indications that the atmospheric sciences $^{1}$ may have the fewest women of all geosciences. A 2005 survey of the American Meteorological Society (AMS) found that $17 \%$ of its members (excluding students) were women. According to 2006 data from the National Science Foundation Scientists and Engineers Statistical Data System, women represented only $15 \%$ of atmospheric and space scientists combined (Gonzales 2010).

The same pattern of underparticipation by women appears to be characteristic of academic atmospheric sciences. Data from the 2002 American Geosciences Institute (AGI) Directory of Geoscience

AFFILIATIONS: MACPHEE-Department of Human Development and Family Studies, Colorado State University, Fort Collins, Colorado; CANETTO-Department of Psychology, Colorado State University, Fort Collins, Colorado

CORRESPONDING AUTHOR: Dr. David MacPhee, Department of Human Development and Family Studies, Colorado State University, 319 Behavioral Sciences Building, Campus Delivery I570, 410 Pitkin Street, Fort Collins, CO 80523-1570 E-mail: david.macphee@colostate.edu

The abstract for this article can be found in this issue, following the table of contents.

DOI:10.1175/BAMS-D-12-00215.1

A supplement to this article is available online (10.1175/BAMS-D-12-00215.2)

In final form 2 April 2014

(C2015 American Meteorological Society
Departments showed that atmospheric sciences programs ranked last among the geosciences in the percentage of women in tenure-stream positions at doctorate-granting institutions - this percentage being around 10\% (Holmes and O'Connell 2003). Similarly, a 2005 survey of the AMS membership noted that women represented $12 \%$ of tenure-stream atmospheric sciences faculty, with $29 \%$ of atmospheric sciences postdoctoral scientists being women. When examined by rank, the AMS survey data showed that women constituted $17 \%$ of assistant professors, $10 \%$ of associate professors, $10 \%$ of full professors, and $1 \%$ of administrators (Tucker et al. 2009). Finally, a National Research Council (NRC) report gave the mean percentage of female faculty members in doctorategranting atmospheric science/meteorology/oceanography at about 16\% in 2006 (Ostriker et al. 2011).

The full participation of women in science, technology, engineering, and math (STEM) fields is increasingly recognized as critical to STEM's vitality and creativity. "With a more diverse workforce, scientific and technological products, services, and solutions are likely to be better designed and more likely to represent all users" states a report of the American Association of University Women (AAUW; Hill et al. 2010, p. 3). According to Chubin and Malcom (2008),

\footnotetext{
${ }^{1}$ Consistent with the approach of Hartten and LeMone (2010), in this article we categorize meteorology and atmospheric science under the general class of atmospheric sciences.
} 
Sooner or later, a White male science ... graduate will sue his alma mater - not because he was denied admission to a special program, but because his education in a homogenous environment left him ill equipped to function in his chosen career, .. . [including being less able to contribute to] a diverse team [or] to satisfy a diverse client market.

Women's participation in STEM fields is also an issue of social justice (Byars-Winston and Canetto 2011) because STEM occupations have median earnings above the national average (Terrell 2007). Engaging more women in STEM occupations has the potential to reduce the income gap between women and men.

First steps in supporting women's participation in STEM occupations are to document women's representation in those occupations, and also to gather information about women training to enter those occupations. This study sought to describe the representation of women among the faculty in U.S. atmospheric sciences programs. More specifically, it aimed to document the proportion, across faculty ranks, of women in U.S. atmospheric sciences doctoral programs, as well as the disciplinary pathways female faculty members took to get to atmospheric sciences academia. This study also examined the proportion of women among atmospheric sciences graduate students as well as the discipline of their undergraduate degrees, their graduation patterns, and their first postgraduate occupational choice-as a way to gauge the characteristics, educational and career pathways, and progress of women potentially in the pipeline for academic positions.

METHOD. Sample. Demographic and professional background information about faculty members in atmospheric sciences was collected in 2009 from the websites of 34 doctoral programs (see Table ES1 at http://dx.doi.org/I0.II75/BAMS-D-I2-002/5.2). Included in the sample were all 10 research-focused atmospheric sciences graduate programs listed in The Chronicle (Wasley 2007). The other 24 programs in the sample were chosen at random from a listing of doctoral programs in atmospheric sciences on PhDs.org (http://graduate-school.phds.org/). Faculty members were included in the sample if they had earned a doctorate and if their appointment involved research responsibilities. Nontenure-track research scientists (i.e., research adjuncts and associates) were included in the sample but nontenure-track teaching faculty (i.e., teaching adjuncts and lecturers) were not. When individuals had a primary appointment in one department and an adjunct appointment at another institution, only the primary appointment was recorded. The final sample included 813 tenuretrack and tenured faculty (66\%), emerita/emeriti faculty (11.6\%), and research scientists (22\%), with a range of 7-55 faculty members per department.

These 34 graduate programs were asked to provide descriptive information about their graduate students. Fifteen of the 34 programs provided information on the 1,153 graduate students who matriculated between 2003 and 2009. Some nonrespondent programs did not have sufficient staff resources to compile the information. Others refused because of confidentiality concerns, or were unresponsive despite multiple e-mail and phone requests. Participant and nonparticipant programs were similar with regard to number of faculty members and graduate students, and also in terms of the representation of women among the faculty.

Procedure. The following information was recorded for each faculty member in the sample: sex, rank (nontenure-track research scientist; tenure-track or tenured assistant, associate, or full professor; and emerita/emeriti faculty); discipline of doctoral degree; and year of doctorate. Faculty members' sex was determined based on website photos and names. Information related to a faculty member's doctoral degree discipline and year of doctoral degree completion was obtained from biographies or curricula vitae posted on the departments' websites. When such information was absent, the data were collected from Digital Dissertations (http://search.proquest.com ladvanced). Information related to the doctoral degree could not be found for 10 faculty members.

For graduate students who matriculated between 2003 and 2009, the programs were asked to supply anonymous data related to their demographic characteristics (e.g., sex, age, and ethnicity), their undergraduate major, and their Graduate Record Examination (GRE) scores. For students who had completed at least two years of graduate school, the programs were also asked to provide information on whether the student had completed a master's or a doctoral degree in the previous seven years. Finally, the programs were asked for data about the initial postgraduate occupation of students who had completed their master's degrees and doctorates between 2003 and 2009. The career tracks were coded as either 1) academia (including postdoctoral, research, and faculty positions at a university); 2) government (e.g., positions at the National Oceanic and Atmospheric Administration, the National Aeronautics and Space Administration, National Center for Atmospheric Research, or a policy 
institute); or 3) private sector (e.g., industry positions).

RESULTS. Women's representation among atmospheric sciences faculty. In 2009 , women constituted $17 \%$ of atmospheric sciences tenure-track or tenured faculty members in the 34 doctorate-granting programs included in this study. The proportion of female faculty members changed to $17.8 \%$ when nontenure-track research scientists were included in the count. Most departments (53\%) had two or fewer female tenure-track or tenured faculty members. The 34 departments differed significantly from each other in the representation of women among the faculty (range $=0 \%$ in three programs to $30 \%$ or more in four programs), $F(33,787)=1.78, p=0.05$, a difference that was not related to the size of the program.

Women's representation among the faculty also differed by academic rank. As shown in Fig. 1, the proportion of women decreased significantly with increasing academic rank, $\chi^{2}(3, n=718)=21.11$, $p<0.0001$. For example, women were $30.4 \%$ of assistant professors but only $11.5 \%$ of full professors. Thirty-four percent of the programs had no female full professor. The underrepresentation of women in academic atmospheric sciences was not explained by time since earning a doctorate: Men and women at the assistant and associate levels had earned their doctorates in the same year, on average, and at the rank of full professor, men were 3 years farther past their doctorate than were women.

Women's representation among atmospheric sciences graduate students. Women constituted 39\% of their entering graduate class over the seven cohorts between 2003 and 2009 in the 15 programs surveyed in this study. At enrollment, female and male graduate students were on average 26.8 and 27.8 years old, respectively. Most female graduate students described themselves as European American (75.3\%), with $14.9 \%$ describing themselves as Asian American, 3\% as Latina, 2\% as African American, $0.6 \%$ as Native American, and $4 \%$ as having multiple ethnic identities. Foreign nationals represented 22\% of the female graduate students and $21 \%$ of the male graduate students. Female and male graduate students did not differ with regard to their age and ethnicity. Small but statistically significant differences between programs were observed in the percentage of female graduate students enrolled (range $=29 \%-53 \%$ ), $F(14,1141)=2.07, p=0.02$. Programs with a higher percentage of pretenure and tenured female faculty members had a higher percentage of female graduate students, $r(14)=0.30$, although this correlation was not statistically significant. No other program characteristic (e.g., students' GRE scores, graduate enrollment, number of faculty) was associated with variations in the representation of women among the graduate students.

\section{Graduation and occupational patterns of atmospheric} sciences graduate students. Data on graduation were available for 1,101 students who had completed at least two years of graduate school between 2003 and 2009. During these years, $44 \%$ of the female students and $42 \%$ of the male students had completed their graduate degrees, while $6.5 \%$ of the female students and $9 \%$ of the male students had left the program, with the remaining students engaged in the program. A test for sex differences in overall degree completion rates was not significant, $\chi^{2}(2, n=1101)=1.98$. However, during the study's time period, significantly fewer female students completed their doctorates as compared to male students ( $21.9 \%$ vs $29.2 \%), z=1.76$, $p=0.04$. Survival analysis ${ }^{2}$ was used to determine

\footnotetext{
${ }^{2}$ Survival analysis is used to analyze data where the outcome variable is the time until the occurrence of an event. Survival analysis is especially appropriate when observations are censored; that is, when information about survival time-in this case, time to degree completion-is incomplete.
} 

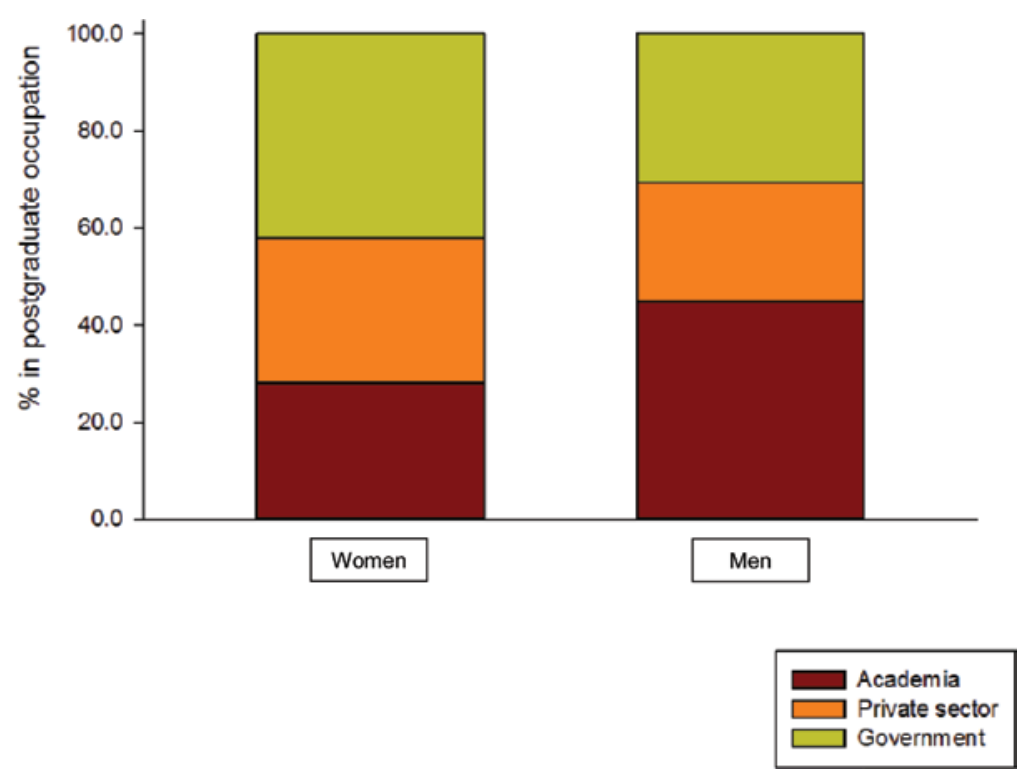

FIG. 2. Percentage of women and men in three occupational tracks in atmospheric sciences, following completion of a graduate degree between 2003 and 2009.

whether the time to degree completion differed by sex but the difference was not statistically significant, Wilcoxon statistic $=2.87, p=0.16$; women took slightly less time than men to complete the master's degree ( $M=2.55$ vs 2.77 years) and slightly more time to complete the doctoral degree $(M=5.29$ vs 5.08 years).

Ten of the graduate programs provided data on the postgraduate occupations of students who had completed a master's degree or a doctorate between 2003 and 2009. Included in the analyses were 224 graduates whose first occupation was related to their degrees. As shown in Fig. 2, female graduates were half as likely to enter academia but were more likely than male graduates to accept positions in government and in the private sector: $\chi^{2}(2, n=224)$ $=7.41, p=0.025$. When the sample was restricted to those who earned their doctorate, it was still the case that fewer female graduates entered academic careers as compared to male students ( $35 \%$ vs $62 \%), z=1.86$, $p=0.03$. Of the doctoral degree completers who went into academia, only $20.4 \%$ were women. Eleven graduates (five women and six men) entered an occupation that was unrelated to their degrees. These occupations were in retail, construction, and recreation, among other job categories.
Disciplinary pathways of female atmospheric sciences faculty and students. To determine women's disciplinary pathways to atmospheric sciences, we first examined faculty members' discipline of doctorate, according to the categories listed in Table 1. The most common doctorate disciplines for atmospheric sciences faculty were atmospheric science and meteorology, together accounting for $58 \%$ of faculty doctorates. Smaller proportions of faculty earned their doctorate in physics, other sciences (including chemistry) and math, or other geosciences. Significant differences by sex were observed in faculty members' doctorate discipline $-\chi^{2}(7$, $n=814)=25.67, p=0.001-$ with women more likely to have earned their doctorates in chemistry $(16 \%$ vs $6 \%$ ) and men more likely to have earned their doctorates in physics ( $14 \%$ vs $8 \%$ ).

One of the factors in women's expanded but not quite equal representation in atmospheric sciences graduate programs may be that the undergraduate feeder majors to the atmospheric sciences have few women. This "crimped pipeline" thesis was examined by first describing which undergraduate majors atmospheric sciences graduate students in our sample came from, and then by using archival data to document the representation of female undergraduate degrees in these feeder majors. A more complete demographic profile of atmospheric sciences graduate programs and their feeder majors is gained by also including
TABLE I. Percentage of atmospheric sciences graduate students by discipline of undergraduate degree and percentage of atmospheric sciences faculty members by discipline of doctorate. Note: The category Other STEM Fields includes chemistry and mathematics; $\mathbf{N}=\mathbf{8 4}$ I graduate students in 15 atmospheric sciences departments, and $N=813$ faculty in 34 atmospheric sciences departments.

\begin{tabular}{|lcc|}
\hline Discipline of degree & Graduate students & Faculty \\
\hline Atmospheric science & 18.2 & 32.9 \\
Engineering & 6.9 & 5.7 \\
Geography & 6.8 & 3.0 \\
Other geosciences & 11.5 & 8.7 \\
Meteorology & 35.2 & 24.7 \\
Physics & 10.9 & 13.0 \\
Other STEM fields & 8.3 & 9.9 \\
\hline
\end{tabular}


the representation of U.S. ethnic minorities. ${ }^{3}$ These pathways are depicted graphically in Fig. 3.

In our sample, most graduate students in atmospheric sciences had undergraduate degrees in atmospheric sciences (either meteorology or atmospheric science), with fewer entering graduate school in atmospheric sciences than other geosciences (e.g., oceanography), physics, or other STEM fields (see Table 1). Significant differences by sex were observed in graduate students' undergraduate major $-\chi^{2}(9, n$ $=841)=24.89, p=0.003$ - with women more likely to have majored in geography ( $9 \%$ vs $5 \%$ ), and men more likely to have majored in engineering ( $9 \%$ vs $4 \%)$ and meteorology (38\% vs $30 \%)$. The percentages from each undergraduate feeder major in Table 1 are represented in Fig. 3 by the length of the arrows indicating how many students entered atmospheric sciences graduate programs from that feeder major. For example, $64.9 \%$ of students admitted to atmospheric sciences graduate programs earned their undergraduate degrees in the geosciences, which in this table included atmospheric science, meteorology, and oceanography.

The pie charts on the left side of Fig. 3 represent the size and composition of the primary undergraduate feeder majors for graduate programs in atmospheric sciences. The size of each pie is relative to the number of undergraduate degrees granted in the discipline in 2008. Data for these pie charts are from the National Science Foundation (www.nsf .gov/statistics/nsfl|3|6/),

${ }^{3}$ Contact the first author for information about these data on U.S. ethnic minority representation in our sample. including the National Science Board (2012), Pandit (2004), the American Institute of Physics (www.aip.org /statistics/trends/undergradtrends.html), and the American Association of Geographers (www.aag .org/cs/projects_and_programs/disciplinary_data /aagcollected_individual_membership_data). For instance, engineering had 16 times more graduates than did either the geosciences or physics. Notable in the undergraduate pie charts are that 1) some majors have more women but comparatively few ethnic minority students (e.g., geography vs engineering),

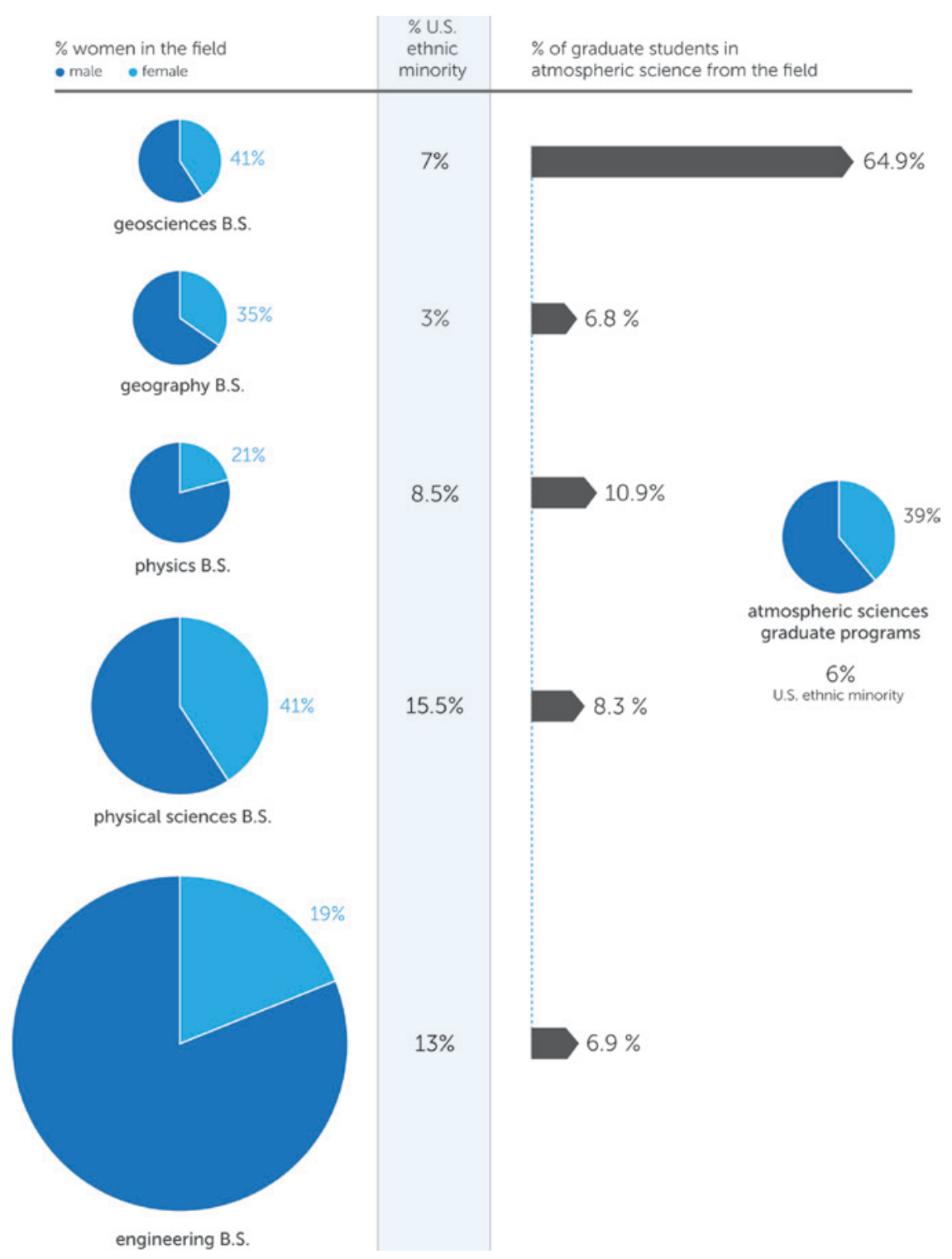

FIG. 3. Primary feeder majors for atmospheric sciences graduate programs. The area of the pie chart for each discipline in the left column is proportionate to the number of undergraduate degrees awarded in 2008 (e.g., 69,446 degrees in engineering vs 5,769 in physics), with pie wedges representing the percentage of women at graduation. The percent U.S. ethnic minority in each field (2008) is represented in the vertical bar. The length of each arrow indicates the percentage of atmospheric sciences graduate students from that field. 
and 2) although few women major in engineering, there are more women who majored in engineering than there are individuals, men and women, who majored in geosciences or in physics. Furthermore, less than $7 \%$ of graduate students in atmospheric sciences had an undergraduate degree in engineering. More generally, few disciplines other than the geosciences contribute students to graduate programs in atmospheric sciences - as is the case with graduate feeder majors into faculty positions (Table 1) - which in large part explains why the graduate pie chart for atmospheric sciences in Fig. 3 closely resembles the undergraduate pie chart for the geosciences.

DISCUSSION AND CONCLUSIONS. This study built upon and expanded prior studies about women in the atmospheric sciences. Our analysis of 34 atmospheric sciences doctorate-granting departments revealed that women represented $17 \%$ of tenure-track or tenured faculty members. The proportion of women in tenure-track or tenured positions was a fraction of the proportion $(39 \%)$ of female graduate students present in the subset of programs surveyed during the same time frame. The data showed that $53 \%$ of departments had two or fewer female tenure-track or tenured faculty members. Also, women's representation among the tenure-stream faculty declined as academic rank increased, with women constituting only $11.6 \%$ of full professors; $34 \%$ of the departments surveyed had no female full professor.

This study's findings suggest a small growth in women's representation in academic atmospheric sciences, relative to the findings of two prior studies-one using 2002 AGI data and the other using 2005 AMS membership survey data (Holmes and O'Connell 2003; Tucker et al. 2009). In 2002 and 2005, women represented $10 \%-12 \%$ of tenure-stream faculty members in atmospheric sciences departments. In other respects, this study's findings are consistent with those of earlier studies (Holmes and O'Connell 2003; Tucker et al. 2009; Winkler et al. 1996), with the presence of women among atmospheric sciences tenure-stream faculty members remaining low and growing at an excruciatingly slow pace, particularly relative to the faster increase in women among the graduate students [see Marschke et al. (2007) for a discussion of demographic inertia in academia].

As a way to track the new cohorts of atmospheric sciences women potentially on a path to academic positions, this study recorded the proportion of women among atmospheric sciences graduate students as well as female graduate students' degree completion patterns and their first occupational destination, relative to their male peers. It was found that at matriculation, women represented $39 \%$ of graduate students. Also, women and men had similar graduate degree completion rates ( $44 \%$ and $42 \%$, respectively). However, significantly fewer women than men completed their doctoral degrees or pursued academic careers upon obtaining their doctorates.

This study's findings on enrollment and degree completion by female students in atmospheric sciences are consistent with and expand those of related studies (e.g., National Science Foundation 2012). Both our study and other reports note that graduate enrollment and degree completion by women in the atmospheric sciences has grown over the decades. For example, according to National Science Foundation (2012) data, in the decade leading to 2009, women received on average $29 \%$ of atmospheric science doctorates, with a peak of $38 \%$ of the doctorates in 2007.

The increasing presence of women among atmospheric sciences graduate students and doctoral degree recipients, and to a lesser degree among atmospheric sciences faculty members, might be interpreted as an indication that women will soon represent half of tenure-stream faculty in atmospheric sciences departments. Clues from both this study and other sources, however, suggest that reaching a balanced representation of women and men in atmospheric sciences academia may be a distant-future proposition. One such clue from this study is that upon completion of the doctorate, women were significantly less likely than men to take a position in academia, consistent with findings from other studies of atmospheric sciences (Tucker et al. 2009; Winkler et al. 1996) as well as other sciences (see, e.g., Newsome 2008 for chemistry). Another clue that it will likely take a long time for women to be well represented among atmospheric sciences tenure-stream faculty is that in this study, as in other studies of faculty in atmospheric sciences (Avallone et al. 2013; Holmes and O'Connell 2003; Tucker et al. 2009; Winkler et al. 1996) and in other STEM fields (e.g., Bailyn 2003; D'Amico et al. 2011; Nolan et al. 2004; Newsome 2008), women are not advancing to higher academic ranks at a pace congruent with their representation in the lower academic ranks.

This study's findings should be interpreted in light of its methodological features, limitations, and strengths. A limitation of this study is that the departments' website data used to collect information about faculty members covered a restricted range of content. Not all information that would have been interesting or important to have about faculty members in 
atmospheric sciences was available via departments' websites. For example, it would have been helpful to have information about the ethnic background of faculty members. This is because the experiences and advancement of faculty members vary significantly not only based on their sex but also depending on their ethnicity (Johnson-Bailey and Cervero 2008; Turner et al. 2011). It would have also been useful to have information about the relationship status (e.g., single vs married) and parental status of faculty members and graduate students in atmospheric sciences. Studies show that couple and parental commitments play a role in women's limited participation and slow advancement in STEM academia, while they have the opposite effect on the careers of men. The reasons why family relationships are capital for men's careers and impediments for women's are complex, having to do primarily with the social expectations that women, independent of their occupational status, put family needs before their career goals, and also that they take primary responsibility for household and caregiving (Canetto et al. 2012; Duberley and Cohen 2010; Ecklund et al. 2012; Libarkin and Kurdziel 2003; Mason and Goulden 2004).

Another limitation of this study is that it is descriptive. Although it documents the participation and the educational pathways of female and male faculty members and students in atmospheric sciences doctoral programs, it does not provide information about the possible causes of the observed patterns. Recent studies of atmospheric sciences faculty members (Avallone et al. 2013) and graduate students (e.g., Canetto et al. 2012) have explored mechanisms that might underlie the patterns documented in this study. Positive role models and proactive mentors, across all career stages, are emerging as important to women's advancement in the atmospheric sciences (Canetto et al. 2012), as they have proven important for the advancement of women in other STEM fields (Nolan et al. 2004; Stout et al. 2011). Studies of women in atmospheric sciences (Canetto et al. 2012; Larocque 1995) suggest that, across career levels, women receive less, and less quality, mentoring than do men. Recent studies also found that women in the atmospheric sciences experience overt discrimination (Avallone et al. 2013; Canetto et al. 2012). A question that remains unanswered is why atmospheric sciences occupations are an outlier within the geosciences with regard to women's participation. According to Kulis et al. (2002), one possibility is that in certain STEM fields, women "have not developed the critical mass that is necessary to overcome tokenism and isolation and to gather sufficient power to compel institutional change" (p. 684). Based on their research, Kulis and colleagues also noted that women's lack of critical mass in academic departments is particularly problematic in disciplines where women tend to be hired as research associates in laboratories and institutes-both a symptom and a cause of women not being viewed as independent scientists.

A strength of this study is that we collected data from a larger and more representative sample of atmospheric sciences faculty members and graduate students than previous studies (e.g., Avallone et al. 2013; Tucker et al. 2009). By using department websites as the source of information about atmospheric sciences faculty members, this study overcame the response-rate limitation associated with survey methods as well as the sample-selectivity limitation associated with using professional organizations' membership samples. Another strength of this study is that it focused on atmospheric sciences departments rather than on a diversity of geosciences departments, as was done in several previous studies (e.g., Ostriker et al. 2011). A single-discipline focus is important given the significant variability in women's participation in different geosciences occupations (Gonzales 2010), including in academia (Ostriker et al. 2011). For all of these reasons, this study generated a more representative and more focused picture of female faculty members and graduate students in the atmospheric sciences academic pipeline.

To conclude, this study contributes new data to the atmospheric sciences community with regard to the representation of women among faculty members and graduate students in doctoral programs. This information is important because a robust and diverse cadre of doctoral-level scientists is critical to a scientific field's vitality and creativity. This study's findings indicate that the talents, perspectives, and experiences of women are still seriously underrepresented among the faculty of doctoral-level atmospheric sciences departments, particularly in senior positions. Also, very few women with doctorates are choosing academic careers. Based on this study's findings and those of related studies (e.g., Holmes et al. 2008; Tucker et al. 2009), the forecast is of a persisting scarcity of women among faculty in atmospheric sciences doctoral programs.

ACKNOWLEDGMENTS. This study was supported in part by the National Science Foundation Center for Multiscale Modeling of Atmospheric Processes, managed by Colorado State University under Cooperative Agreement ATM-0425247. The conclusions and recommendations found in this article are those of the authors and do not 
necessarily represent the official views, opinions, or policy of the National Science Foundation. The authors acknowledge Greg Rattenborg's assistance with the graphics.

\section{REFERENCES}

Avallone, L. M., A. G. Hallar, H. Thiry, and L. M. Edwards, 2013: Supporting the retention and advancement of women in the atmospheric sciences: What women are saying. Bull. Amer. Meteor. Soc., 94, 1313-1316, doi:10.1175/BAMS-D-12-00078.1.

Bailyn, L., 2003: Academic careers and gender equity: Lessons learned from MIT. Gender Work Organ., 10, 137-152, doi:10.1111/1468-0432.00008.

Byars-Winston, A., and S. S. Canetto, 2011: Accomplishments and challenges for a diversity of women in science, technology, engineering, and mathematics education and occupations. J. Women Minorities Sci. Eng., 17, 1-3, doi:10.1615/JWomenMinorScienEng.v17.i1.10.

Canetto, S. S., C. D. Trott, J. J. Thomas, and C. A. Wynstra, 2012: Making sense of the atmospheric science gender gap: Do female and male students have different career motives, goals, and challenges? J. Geosci. Educ., 60, 408-416, doi:10.5408/12-296.1.

Chubin, D. E., and S. M. Malcom, 2008: Making a case for diversity in STEM fields. Inside Higher Ed. [Available online at www.insidehighered.com /views/2008/10/06/chubin.]

D’Amico, R., P. Vermigli, and S. S. Canetto, 2011: Publication productivity and career advancement by female and male psychology faculty: The case of Italy. J. Diversity Higher Educ., 4, 175-184, doi:10.1037 /a0022570.

Duberley, J., and L. Cohen, 2010: Gendering career capital: An investigation of scientific careers. J. Voc. Behav., 76, 187-197, doi:10.1016/j.jvb.2009.09.005.

Ecklund, E. H., A. E. Lincoln, and C. Tansey, 2012: Gender segregation in elite academic science. Gender Soc., 26, 693-717, doi:10.1177/0891243212451904.

Gonzales, L., 2010: Participation of women in geoscience occupations. American Geosciences Institute Geoscience Currents 33. [Available online at www.agiweb.org/workforce/Currents/Currents -033-GenderOccupations.pdf.]

Hartten, L. M., and M. A. LeMone, 2010: The evolution and current state of the atmospheric sciences “pipeline.” Bull. Amer. Meteor. Soc., 91, 942-956, doi:10.1175/2010BAMS2537.1.

Hill, C., C. Corbett, and A. St. Rose, 2010: Why so few? Women in science, technology, engineering, and mathematics. American Association of University Women Research Rep., 109 pp. [Available online at www.aauw.org/files/2013/02/Why-So-Few -Women-in-Science-Technology-Engineering-and -Mathematics.pdf.]

Holmes, M. A., and S. O'Connell, 2003: Where are the women geoscience professors? University of Nebraska-Lincoln Papers in the Earth and Atmospheric Sciences, 41 pp. [Available online at http:// digitalcommons.unl.edu/cgi/viewcontent.cgi?article $=1085 \&$ context $=$ geosciencefacpub. $]$

- - — C. Frey, and L. Ongley, 2008: Gender imbalance in US geoscience academia. Nat. Geosci., 1, 79-82, doi:10.1038/ngeo113.

Johnson-Bailey, J., and R. M. Cervero, 2008: Different world and divergent paths: Academic careers defined by race and gender. Harv. Educ. Rev., 78, 311-332.

Kulis, S., D. Sicotte, and S. Collins, 2002: More than a pipeline problem: Labor supply constraints and gender stratification across academic science disciplines. Res. Higher Educ., 43, 657-691, doi:10.1023/A:1020988531713.

Larocque, A. C. L., 1995: Challenges and rewards of graduate studies in the geosciences: A woman's perspective. Geosci. Can., 21, 129-132.

Libarkin, J. C., and J. P. Kurdziel, 2003: Research methodologies in science education: Gender and the geosciences. J. Geosci. Educ., 51, 446-452.

Marschke, R., S. Laursen, J. M. Nielsen, and P. Rankin, 2007: Demographic inertia revisited: An immodest proposal to achieve equitable gender representation among faculty in higher education. J. Higher Educ., 78, 1-26, doi:10.1353/jhe.2007.0003.

Mason, M. A., and M. Goulden, 2004: Marriage and baby blues: Redefining gender equity in the academy. Ann. Amer. Acad. Polit. Soc. Sci., 596, 86-103, doi:10.1177/0002716204268744.

National Science Board, 2012: Science and engineering indicators 2012. National Science Foundation NSB 12-01. [Available online at www.nsf.gov/statistics /seind12/.]

National Science Foundation, 2012: S\&E doctoral degrees awarded to women, by field: 2001-09. Women, minorities, and persons with disabilities in science and engineering: 2012, Table 7-2. [Available online at www.nsf.gov/statistics/wmpd/2012-01 /tables/tab7-2.xls.]

Newsome, J. L., 2008: The chemistry PhD: The impact on women's retention. Royal Society of Chemistry and the U.K. Resource Centre for Women in SET, 38 pp. [Available online at www.biochemistry.org /Portals/0/SciencePolicy/Docs/Chemistry\%20 Report\%20For\%20Web.pdf.]

Nolan, S. A., J. P. Buckner, V. J. Kuck, and C. H. Marzabadi, 2004: Analysis by gender of the doctoral 
and postdoctoral institutions of faculty members at the top-fifty ranked chemistry departments. J. Chem. Educ., 81, 356-363, doi:10.1021/ed081p356.

Ostriker, J. P., C. V. Kuh, and J. A. Voytuk, Eds., 2011: A Data-Based Assessment of Research-Doctorate Programs in the United States. The National Academies Press, 322 pp.

Pandit, K., 2004: Geography's human resources over the past half-century. Prof. Geogr, 56, 12-21.

Stout, J. G., N. Dasgupta, M. Hunsinger, and M. A. McManus, 2011: STEMing the tide: Using ingroup experts to inoculate women's self-concept in science, technology, engineering, and mathematics (STEM). J. Pers. Soc. Psychol., 100, 255-270, doi:10.1037 /a0021385.

Terrell, N., 2007: STEM occupations. Occupational Outlook Quarterly, No. 1, Bureau of Labor Statistics, Washington, DC, 26-33. [Available online at www .bls.gov/opub/ooq/2007/spring/art04.pdf.]
Tucker, D., D. K. Ginther, and J. A. Winkler, 2009: Gender issues among academic AMS members: Comparisons with the 1993 membership survey. Bull. Amer. Meteor. Soc., 90, 1180-1191, doi:10.1175/2009BAMS2538.1.

Turner, C. S. V., J. C. Gonzáles, and K. Lau Wong, 2011: Faculty women of color: The critical nexus of race and gender. J. Diversity Higher Educ., 4, 199-211, doi:10.1037/a0024630.

Wasley, P., 2007: Top research universities faculty scholarly productivity index: Atmospheric sciences and meteorology (2007). [Available online at http:// chronicle.com/stats/productivity/page.php?bycat $=$ true \& primary $=4 \&$ secondary $=130$ \&year $=2007$.

Winkler, J. A., D. Tucker, and A. K. Smith, 1996: Salaries and advancement of women faculty in atmospheric science: Some reasons for concern. Bull. Amer. Meteor. Soc., 77, 473-490, doi:10.1175/1520 -0477(1996)0772.0.CO;2.

\section{NEW FROM AMS BOOKS!}

\section{"A thoughtful analysis of actions that we need to take to reduce the impacts of extreme weather... a must-read for everyone with an interest in the weather and climate." \\ - FRANKLIN W. NUTTER, \\ President, Reinsurance Association of America}

\section{Living on the Real World: How Thinking and Acting Like Meteorologists Will Help Save the Planet WILLIAM H. HOOKE}

Meteorologists sift through a deluge of information to make predictions every day. Instead of being overwhelmed by the data and possibilities, they focus on small bits of information while using frequent collaboration to make decisions. With climate change a reality, William $\mathrm{H}$. Hooke suggests we look to the way meteorologists operate as a model for how we can solve the twenty-first century's most urgent environmental problems. 
Hurricane Pioneer:

Memoirs of

Bob Simpson

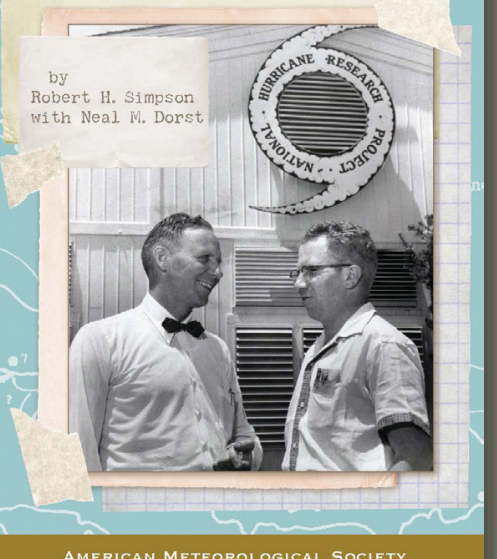

AMERICAN METEOROLOGICAL SOCIETY
Browse online at ametsoc.org/bookstore

FREE SHIPPING for AMS Members!

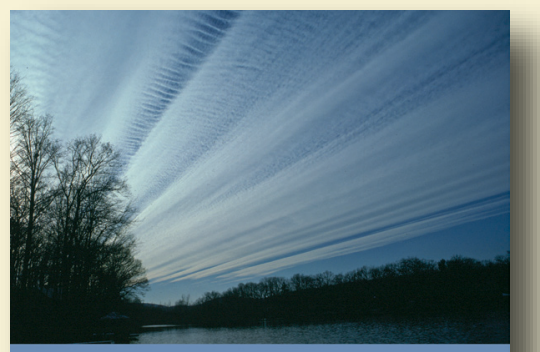

AN OBSERVER'S GUIDE to

\section{CLOUDS AND WEATHER}

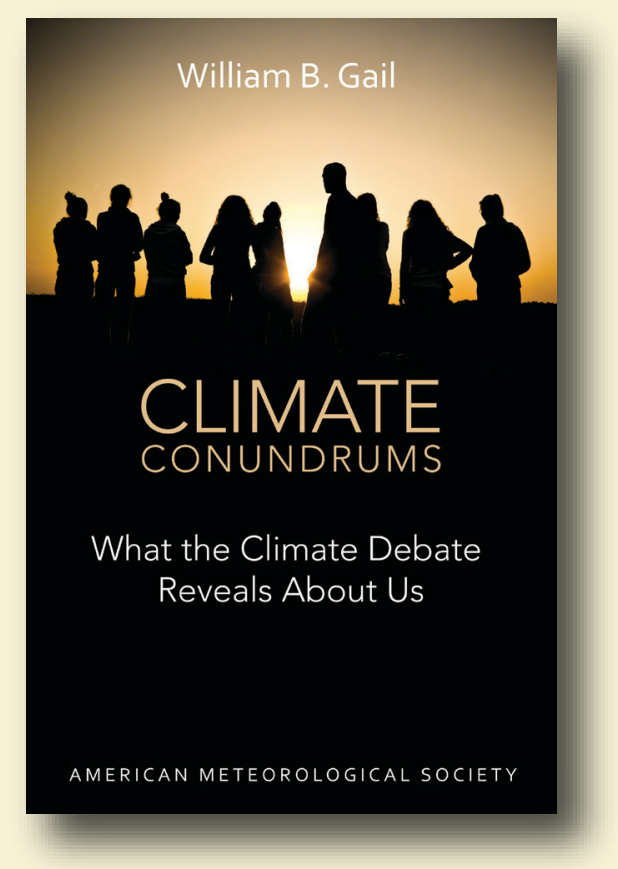

\section{CLIMATE CONUNDRUMS}

What the Climate Debate Reveals

About Us

William B. Gail

This is a journey through how we think, individually and collectively, derived from the climate change debate. With wit and wisdom, Gail explores several questions: Can we make nature better? Could science and religion reconcile? Insights from such issues can help us better understand who we are and help society find a way forward.

\section{(C) 2014, PAPERBACK}

ISBN: 978-1-935704-74-4

LIST \$30 MEMBER \$20

\section{AN OBSERVER'S GUIDE TO CLOUDS AND WEATHER}

A Northeast Primer on Prediction

Toby Carlson, Paul Knight, and Celia Wykoff

With help from Penn State experts, start at the beginning and go deep. This primer for enthusiasts and new students alike will leave you with both refined observation skills and an understanding of the complex science behind the weather: the ingredients for making reliable predictions of your

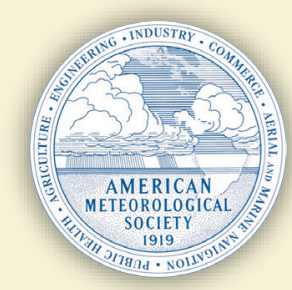

\section{AMS BOOKS}

AMS Books are available to groups and booksellers, and desk copies may be obtained, through our distributor 